\title{
Generalized Self-Driven AC-DC Synchronous Rectification Techniques for Single- and Multiphase Systems
}

\author{
W. X. Zhong, W. P. Choi, Wing W. C. Ho, Member, IEEE, and S. Y. Hui, Fellow, IEEE
}

\begin{abstract}
This paper extends the single-phase self-driven synchronous rectification (SDSR) technique to multiphase ac-dc systems. Power MOSFETs with either voltage- or current-sensing self-driven gate drives are used to replace the diodes in the rectifier circuits. The generalized methodology allows multiphase SDSRs to be designed to replace the multiphase diode rectifiers. Unlike the traditional SR that is designed for high-frequency power converters, the SDSR proposed here can be a direct replacement of the power diode bridges for both low- and high-frequency operations. The SDSR utilizes its output de voltage to supply power to its control circuit. No start-up control is needed because the body diodes of the power MOSFETs provide the diode rectifier for the initial start-up stage. The generalized method is demonstrated in 2-kW one-phase and three-phase SDSRs for inductive, capacitive, and resistive loads. Power loss reduction in the range of 50\%-69\% has been achieved for the resistive load.
\end{abstract}

Index Terms-Energy saving, mains-frequency synchronous rectifiers, self-driven synchronous rectifiers.

\section{INTRODUCTION}

$\mathbf{S}$ YNCHRONOUS rectifiers based on the use of power MOSFETs to replace the diodes in reducing the conduction losses have been widely used in low-voltage high-current applications since 1990 [1]. Synchronous rectifier techniques are primarily applied to various versions of $\mathrm{dc}-\mathrm{dc}$ converters such as buck converters [2], [3], flyback and boost-buck converters [4], [5], half-bridge converters [6], [7], and $L C C$ resonant converters [8], [9]. To reduce the cost of the gate-drive circuits, self-driven techniques have been an active research topic in synchronous rectifiers [2], [7], [9], [10], although the gate control integrated circuit for driving synchronous rectifiers is also commercially available [11]. Other research aspects include the use of the soft-switching technique [6], [9], [12]. Besides

Manuscript received May 6, 2010; revised August 24, 2010; accepted October 4, 2010. Date of publication November 9, 2010; date of current version July 13, 2011. This work was supported by the Center for Power Electronics, City University of Hong Kong.

W. X. Zhong, W. P. Choi, and W. W. C. Ho are with the Center for Power Electronics, Department of Electronic Engineering, City University of Hong Kong, Kowloon, Hong Kong.

S. Y. Hui is with the Center for Power Electronics, Department of Electronic Engineering, City University of Hong Kong, Kowloon, Hong Kong, and also with the Department of Electrical \& Electronic Engineering, Imperial College, SW7 2AZ London, U.K. (e-mail: eeronhui@cityu.edu.hk; r.hui@imperial.ac.uk).

Color versions of one or more of the figures in this paper are available online at http://ieeexplore.ieee.org.

Digital Object Identifier 10.1109/TIE.2010.2090835 the dc-dc converters, the synchronous rectification techniques have been applied to the three-phase full-bridge ac-dc converter based on a three-phase fully controlled bridge [13] and even to the five-level converter [14]. While the self-driven technique uses the changing voltage polarity of the coupled windings to control the switching of the power MOSFETs, other techniques tend to use control integrated circuits to provide the gating signals.

An attempt to replace a general-purpose diode bridge with a synchronous rectifier for low-power and low-voltage (3-5 V) applications appears in [15] in which the synchronous rectification technique is applied to a center-tap rectifier topology. A customized charge pump circuit is however needed in the proposal of [15] in order to provide a suitable dc power supply for the gate drive. As such proposal aims at low-voltage applications, it is not suitable for high-voltage mains voltage operations. For a high-power and mains-frequency operation, a synchronous rectifier technique has been previously proposed [16]. It is based on the detection of the phase-phase voltage, and sophisticated logic and timing circuits are needed to provide the gating signals if the ac source has a significant source inductance. However, the gating signals for the synchronous rectifiers based on voltage detection are not adequate because the diodes of a traditional bridge rectifier only turn off after their current reverse-recovery processes.

It has been pointed out in [17] and [18] that it is more appropriate to use at least one current-sensed gate drive in each current loop of the synchronous rectifier for general power applications unless there is an external circuit that will be used to cut off the current for the rectifier. In this paper, the principle of ac-dc synchronous rectification based on the self-sensing and self-driven control circuit is generalized from single-phase systems to multiphase ones for both low- and high-voltage applications and for both low- and high-frequency operations. Power MOSFETs with either voltage or current self-sensing and self-driven gate drives are used to replace the diodes in the rectifier circuits. New self-driven synchronous rectification (SDSR) circuits are designed to behave like the traditional diode rectifiers, except that their conduction loss is much smaller than that of the diode rectifiers. This principle is successfully and practically demonstrated in a three-phase synchronous rectifier for capacitive, inductive, and resistive loads, with the significant loss reduction exceeding $50 \%$ when compared with a diode bridge at both 110 and $220 \mathrm{~V}$ mains. Consequently, the thermal management and heat 


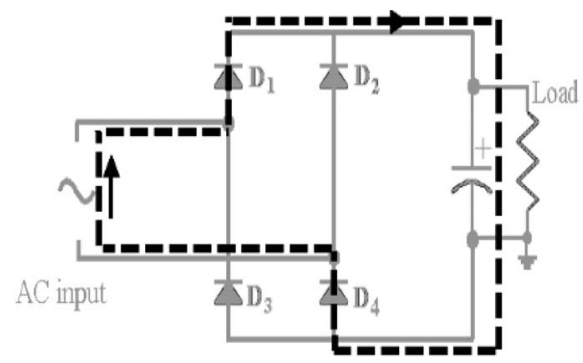

(a)

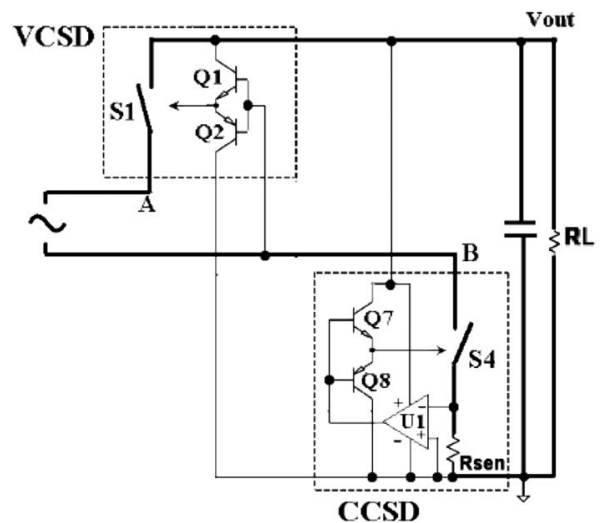

(b)

Fig. 1. (a) One conducting path via two diodes. (b) A conducting path via one VCSD and one CCSD.

sink requirements are reduced, and a more compact rectifier can be achieved for general-purpose ac-dc applications. In this paper, Section II outlines the generalized SDSR principle. The hardware implementation is illustrated in Section III using a three-phase SDSR as an example. The measurements on the single- and three-phase SDSRs and their diode rectifier counterparts are included in Section IV. Finally, we conclude in Section V.

\section{Generalized SDSR PRINCIPLE}

\section{A. Single-Phase Rectification System}

Starting with a single-phase diode rectifier, this section describes the general principle behind the proposal. Fig. 1(a) shows one conduction loop of a diode rectifier. As the input ac voltage reverses and the current starts to reverse, the diodes will turn off after the current reverse recovery. This means that the power MOSFETs that replace the diodes in the SDSR should turn off when the sensed current begins to reverse. However, it should be noted that, as long as one MOSFET is turned off, the current path is cut off. Therefore, the first principle of this generalized method is that at least one of the power MOSFETs should have a "self-sensing" current-controlled selfdriven (CCSD) gate drive. The CCSD MOSFET is controlled in such a manner that, by sensing the branch current, the MOSFET is turned on when the current is larger than a small threshold value (e.g., $0.1 \mathrm{~A}$ ) and is then turned off so that its body diode will carry a current less than the threshold current and will perform the diode reverse recovery for full turn-off of the CCSD switch. The voltage-controlled self-driven (VCSD) MOSFET relies on voltage sensing of only the ac mains voltage. Since the
TABLE I

Logic Assignments of Different Circuit Elements

\begin{tabular}{|c|ccccc|}
\hline & CCSD & Diode & Inductor & VCSD & Capacitor \\
$X$ & $I$ & $D$ & $L$ & $V$ & $C$ \\
\hline$S X$ & 1 & 1 & 1 & 0 & 0 \\
\hline
\end{tabular}

CCSD gate drive is more complicated than the "self-sensing" VCSD gate drive, as shown in Fig. 1(b), it is proposed that one CCSD and one VCSD gate drive should be used in each current loop in the synchronous rectifier. In Fig. 1(b), a currentsensing resistor $R_{\text {sen }}$ is used to provide the feedback signal for the CCSD gate drive. In principle, the ON-state resistance of the power MOSFET can be used as the current-sensing resistor if desired.

A systematic way of generalizing an ac-dc SDSR system is shown as follows. Let $X$ be a circuit component that can be one of the following: a diode (D), an inductor $(L)$, a capacitor $(C)$, a CCSD active switch (CCSD), and a VCSD active switch (VCSD). The location of the upper elements in a rectifier is defined by the subscript $i$ of the circuit element symbol $X_{i}$. For the upper branch elements $X_{i}$

$$
i=1,2, \ldots, n \text {. }
$$

For the lower branch elements $X_{j}$

$$
j=n+1, n+2, \ldots, 2 n
$$

where $n$ is the number of converter branches. For example, for a single-phase rectifier

$$
n=2 .
$$

The numbers of the upper elements are one and two, and the numbers of the lower elements are three and four, as shown in Fig. 1(a).

A logic value is assigned to each circuit element $X_{i}$ or $X_{j}$ (which can be an active switch, a diode, or other circuit element), which is represented by

$$
\begin{array}{ll}
S X_{i}, & i=1,2, \ldots, n \\
S X_{j}, & j=n+1, n+2, \ldots, 2 n .
\end{array}
$$

For the circuit element showing the capability of the resisting instantaneous current change, a logic value of " 1 " is assigned. Therefore, "1" is assigned to a CCSD active switch, a diode, and an inductor. A VCSD active switch and a capacitor have no such capability of resisting the instantaneous current change. Therefore, they have been assigned a logic value of "0." Table I shows the corresponding logic value for each circuit element.

In a bridge rectifier, each current loop $\left\{X_{i}, X_{j}\right\}$ can be identified by the branch location in the circuit, and an associated circuit element logic value in the branch can be mapped in the corresponding current loop

$$
\left\{X_{i}, X_{j}\right\} \rightarrow\left\{S X_{i}, S X_{j}\right\} .
$$

In order to achieve the function of the SDSR in a rectifier, it requires that at least one CCSD active switch, inductor, or diode must be present in each current loop of a rectifier. The 


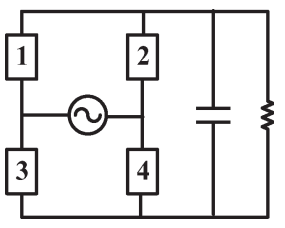

Fig. 2. Structure of a single-phase synchronous rectifier.

aforementioned circuit elements have the capability of blocking a reverse current flow and changing to the OFF state automatically. Therefore, the logical "OR" function of two circuit elements in a current loop must be equal to " 1 " such that the SDSR mechanism can be realized.

In the following analysis of the different possible configurations, the following terminology is used:

$S X_{i} \cup S X_{j}=1$ means that a correct combination of circuit elements exists in a current loop;

$S X_{i} \cup S X_{j}=0$ means that an incorrect combination of circuit elements exists in a current loop.

For a single-phase rectifier with four elements (Fig. 2), there are 16 (i.e., $2^{4}$ ) possibilities. Table II defines the nine valid topologies of a full-bridge rectifier and the associated current loops, where the upper branches comprise circuit elements 1 and 2, while the lower branches comprise circuit elements 3 and 4. Some examples that are of particular practical significance are given here to demonstrate the general SDSR principle based on the configurations listed in Table II. These configurations are highlighted in bold in Table II.

Configuration 1 of Table II can be realized by the circuit shown in Fig. 3, where the two upper elements $S X_{1}$ and $S X_{2}$ are VCSD active switches (with logic "0") and the two lower elements $S X_{3}$ and $S X_{4}$ are CCSD active switches (with logic "1"). This is an example that will be studied in this paper for practical demonstration.

Configuration 4 of Table II can be used to develop a halfbridge rectifier or a voltage doubler, as shown in Fig. 4, where elements 1 and 3 are CCSD active switches (with logic "1") and elements 2 and 4 are capacitors (with logic " 0 "). Configuration 9 of Table II can lead to the implementation of a single-phase current doubler, as shown in Fig. 5, where $S X_{1}$ and $S X_{2}$ are inductors and $S X_{3}$ and $S X_{4}$ are CCSD active switches.

\section{B. Multiphase Rectification Systems}

The principle can be generalized to a multiphase system. For example, a three-phase ac-dc converter (Fig. 6) consists of six elements. Based on the generalized method, the valid configurations are listed in Table III. Out of the 64 (i.e., $2^{6}$ ) possible arrangements, 18 configurations are valid for the threephase synchronous rectification.

From the single- and three-phase systems, it can be seen that, for a two-level (standard) rectification, the number of valid configurations $\left(N_{v}\right)$ obeys the following equation:

$$
N_{v}=2^{n+1}+n-1
$$

where $n$ is the number of converter branches (i.e., two for the single phase and three for the three phase).
Two examples that are based on Table III are used to illustrate the general principle. Fig. 7 shows a three-phase half synchronous rectifier based on configuration 8 of Table III. The three upper elements are diodes, and the three lower elements are VCSD active switches. This arrangement reduces the conduction losses in only three diodes when compared with a threephase diode bridge. A three-phase full synchronous rectifier based on configuration 1 of Table III is shown in Fig. 8, where the three upper elements are VCSD active switches and the three lower elements are CCSD active switches.

\section{SElF-Driven GATE-Drive Circuitry}

The low-power self-driven gate-drive circuitry for a threephase synchronous rectifier is used to illustrate the operating principle of a multiphase SDSR system. As shown in Fig. 9, six power MOSFETs $\left(M_{1}\right.$ to $\left.M_{6}\right)$ form the main circuit for the three-phase full-wave rectification. The self-driven gatedrive circuits for the six MOSFETs, highlighted in shaded boxes, are powered by the output dc voltage of the SDSR, and they consume a low power. The circuitry can, in principle, be integrated in the same rectifier package. The whole circuit can be divided into two parts: high- and low-side circuits. Both high- and low-side parts are symmetrical. The six body diodes of the power MOSFETs $\left(\mathrm{M}_{1}\right.$ to $\left.\mathrm{M}_{6}\right)$ form a standard diode bridge. This means that, even if the gate-drive circuits are not ready for operation immediately at the start-up of the circuit, this standard diode bridge is inherent in the proposed circuit, which is used to perform the function of rectification before the gate-drive circuitry is ready.

\section{A. Operating Principle-Initial Gate-Drive Start-Up}

As shown in Fig. 9, there are three capacitors in each of the three high-side driving circuits $\left(C_{1}, C_{2}\right.$, and $C_{3}$ for $\mathrm{M}_{1}$; $C_{4}, C_{5}$, and $C_{6}$ for $\mathrm{M}_{2}$; and $C_{7}, C_{8}$, and $C_{9}$ for $\mathrm{M}_{3}$ ). Each upper gate drive has three driving stages. Taking $\mathrm{M}_{1}$ as an example, $\mathrm{Q}_{2}$ to $\mathrm{Q}_{5}, \mathrm{M}_{7}$ and $\mathrm{M}_{8}$, and $\mathrm{Q}_{6}$ and $\mathrm{Q}_{7}$ form the three driving stages. $Q_{2}$ to $Q_{5}$ form the first logic stage, and they are for signal amplification and for providing charging paths for the capacitors acting as power supplies. $M_{7}$ and $M_{8}$ form an intermediate inverter stage. $Q_{6}$ and $Q_{7}$ form a fast and final driving stage for the power MOSFET $\mathrm{M}_{1} . C_{3}, C_{6}$, and $C_{9}$ are charged as the power supplies in driving the first logic stages for $\mathrm{M}_{1}, \mathrm{M}_{2}$, and $\mathrm{M}_{3}$, respectively. Before $C_{3}, C_{6}$, and $C_{9}$ are charged up to a certain threshold voltage, e.g., $10 \mathrm{~V}$, the driving logic in the circuit will not be active. $C_{1}, C_{4}$, and $C_{7}$ will be charged up as the power supplies of the intermediate and final driving stages for the three upper MOSFETs. In the start-up stage, $C_{2}, C_{5}$, and $C_{8}$ are designed to be charged up faster than $C_{3}, C_{6}$, and $C_{9}$, until their voltages reach a certain level clamped by the Zener diodes $\mathrm{D}_{\mathrm{Z} 1}, \mathrm{D}_{\mathrm{Z} 2}$, and $\mathrm{D}_{\mathrm{Z} 3}$. Bipolar transistors $\mathrm{Q}_{1}, \mathrm{Q}_{8}$, and $\mathrm{Q}_{15}$ are used to ensure that $C_{1}, C_{4}$, and $C_{7}$ will not be charged before $C_{3}, C_{6}$, and $C_{9}$ have been charged up to a voltage higher than the voltage of $C_{2}, C_{5}$, and $C_{8}$. Therefore, MOSFETs $\mathrm{M}_{1}, \mathrm{M}_{2}$, and $\mathrm{M}_{3}$ will not switch before the driving logic has been set up. 
TABLE II

VALid Configurations of a Single-Phase Synchronous Rectifier

\begin{tabular}{|c|cccc|cc||c|}
\hline & \multicolumn{4}{|c|}{ Logic Value of Circuit Element } & A & B & Valid SR \\
Config.
\end{tabular}

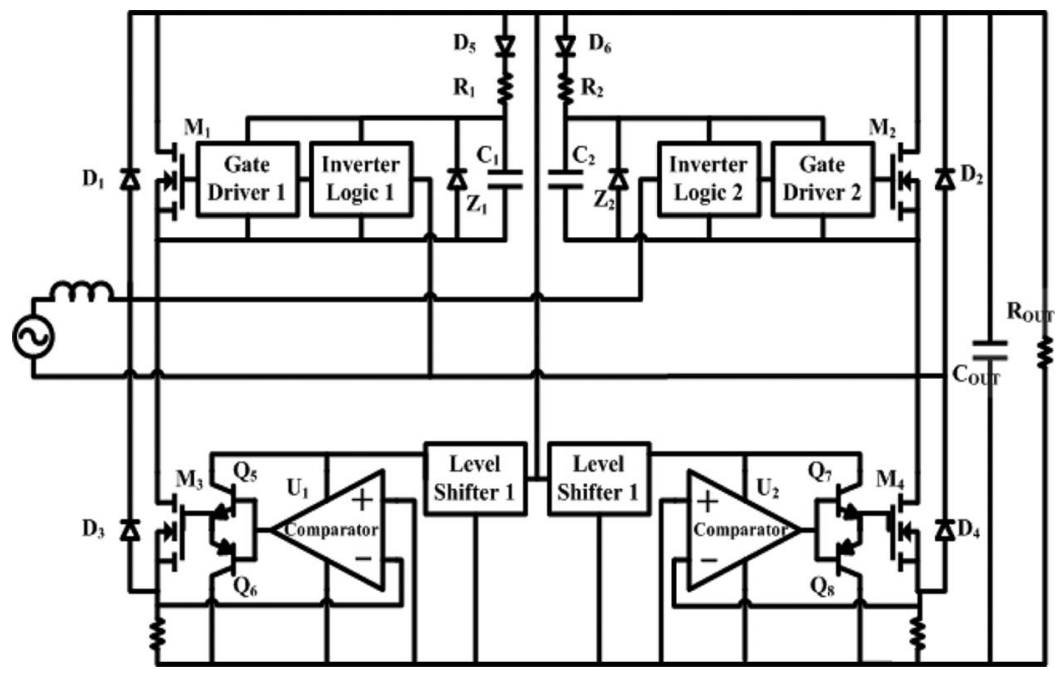

Fig. 3. Practical high-voltage circuit for a single-phase full-bridge rectifier based on configuration 1 of Table II.

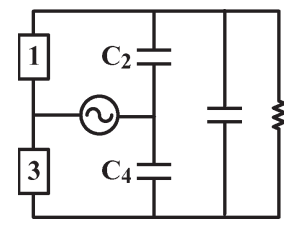

Fig. 4. Schematic of a half-bridge rectifier or voltage doubler on configuration 4 of Table II.

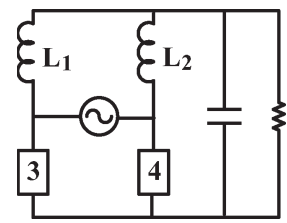

Fig. 5. Schematic of a current doubler based on configuration 9 of Table II.

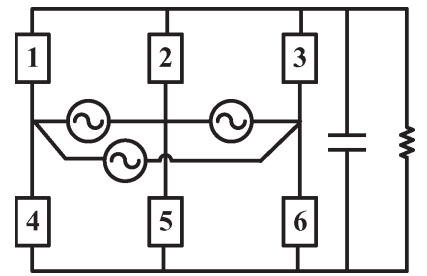

Fig. 6. Basic structure of a three-phase synchronous rectifier.

\section{B. Operation Principle of the Upper Gate Drives}

The transitional period shaded in Fig. 10 is used to illustrate the operation of the upper gate drive. We use $v_{B C n}$ to represent the base-collector voltages of the BJT $\mathrm{Q}_{n}$. The voltage across $C_{1}, C_{4}$, and $C_{7}$ is assumed to be at a constant level $V$. In this period, the output phase will change from phase $A$ to phase $B$. Therefore, $\mathrm{M}_{1}$ should be turned off, and $\mathrm{M}_{2}$ should be turned on at the commutation point. Because the phase voltage $v_{C}$ is the lowest, therefore $v_{B C 3}$ and $v_{B C 12}$ are clamped to zero $(0.7 \mathrm{~V}$ to be precise) by the p-n junctions between the collector and the base of $\mathrm{Q}_{3}$ and $\mathrm{Q}_{12}$. With the aid of the timing diagram in Fig. 11, the operation of the upper gate drives can be explained as follows.

1) Before $t_{1}: v_{A B}$ is higher than $V$. Both current directions in $R_{7}$ and $R_{8}$ are from left to right, as shown in Fig. 12(a). $v_{B C 5}$ is clamped zero by the collector-base p-n junction of $\mathrm{Q}_{5}$. Therefore, the p-channel MOSFET $\mathrm{M}_{7}$ is on, and the $\mathrm{n}$-channel MOSFET $\mathrm{M}_{8}$ is off. Such condition keeps the gate-source voltage of $\mathrm{M}_{1}$ high, thus turning it on. Meanwhile, the current in $R_{8}$ flows through the base-collector p-n junction of $\mathrm{Q}_{9}$, which clamps $v_{B C 10}$ at $V$. Because $\mathrm{D}_{2}$ is reverse biased, the gate-source voltage of $\mathrm{M}_{10}$ is kept at $V$. Therefore, $\mathrm{M}_{9}$ is off, 
TABLE III

VALid CONFIGURATIONS OF A THREE-PHASE SynCHRONOUS RECTIFIER

\begin{tabular}{|c|c|c|c|c|c|c|c|c|c|c|c|c|c|}
\hline & \multicolumn{6}{|c|}{ Logic Value of Circuit Element } & $A$ & $B$ & $C$ & $D$ & $E$ & $F$ & Valid Config. \\
\hline $\begin{array}{l}\text { Congfig. } \\
\text { No. }\end{array}$ & $S X_{1}$ & $S X_{2}$ & $S X_{3}$ & $S_{4}$ & $S X_{5}$ & $S X_{6}$ & $S X_{1} \cup S X_{5}$ & $S X_{1} \cup S X_{6}$ & $S X_{2} \cup S X_{4}$ & $S X_{2} \cup S X_{6}$ & $S X_{3} \cup S X_{4}$ & $S X_{3} \cup S X_{5}$ & $\begin{array}{c}A \cap B \cap C \cap D \\
\cap E \cap F\end{array}$ \\
\hline 1 & 0 & 0 & 0 & 1 & 1 & 1 & 1 & 1 & 1 & 1 & 1 & 1 & 1 \\
\hline 2 & 0 & 0 & 1 & 1 & 1 & 1 & 1 & 1 & 1 & 1 & 1 & 1 & 1 \\
\hline 3 & 0 & 1 & 0 & 1 & 1 & 1 & 1 & 1 & 1 & 1 & 1 & 1 & 1 \\
\hline 4 & 0 & 1 & 1 & 1 & 1 & 1 & 1 & 1 & 1 & 1 & 1 & 1 & 1 \\
\hline 5 & 1 & 0 & 0 & 1 & 1 & 1 & 1 & 1 & 1 & 1 & 1 & 1 & 1 \\
\hline 6 & 1 & 0 & 1 & 1 & 1 & 1 & 1 & 1 & 1 & 1 & 1 & 1 & 1 \\
\hline 7 & 1 & 1 & 0 & 1 & 1 & 1 & 1 & 1 & 1 & 1 & 1 & 1 & 1 \\
\hline 8 & 1 & 1 & 1 & 0 & 0 & 0 & 1 & 1 & 1 & 1 & 1 & 1 & 1 \\
\hline 9 & 1 & 1 & 1 & 0 & 0 & 1 & 1 & 1 & 1 & 1 & 1 & 1 & 1 \\
\hline 10 & 1 & 1 & 1 & 0 & 1 & 0 & 1 & 1 & 1 & 1 & 1 & 1 & 1 \\
\hline 11 & 1 & 1 & 1 & 0 & 1 & 1 & 1 & 1 & 1 & 1 & 1 & 1 & 1 \\
\hline 12 & 1 & 1 & 1 & 1 & 0 & 0 & 1 & 1 & 1 & 1 & 1 & 1 & 1 \\
\hline 13 & 1 & 1 & 1 & 1 & 0 & 1 & 1 & 1 & 1 & 1 & 1 & 1 & 1 \\
\hline 14 & 1 & 1 & 1 & 1 & 1 & 0 & 1 & 1 & 1 & 1 & 1 & 1 & 1 \\
\hline 15 & 0 & 1 & 1 & 0 & 1 & 1 & 1 & 1 & 1 & 1 & 1 & 1 & 1 \\
\hline 16 & 1 & 0 & 1 & 1 & 0 & 1 & 1 & 1 & 1 & 1 & 1 & 1 & 1 \\
\hline 17 & 1 & 1 & 0 & 1 & 1 & 0 & 1 & 1 & 1 & 1 & 1 & 1 & 1 \\
\hline 18 & 1 & 1 & 1 & 1 & 1 & 1 & 1 & 1 & 1 & 1 & 1 & 1 & 1 \\
\hline
\end{tabular}

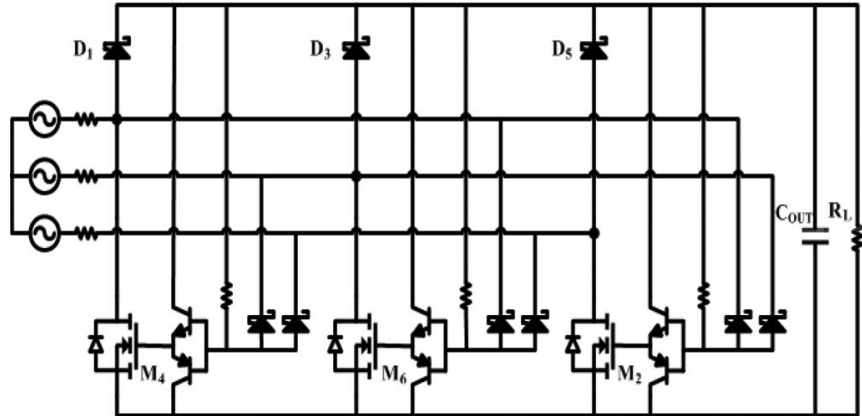

Fig. 7. Three-phase half synchronous rectifier for low-voltage applications.

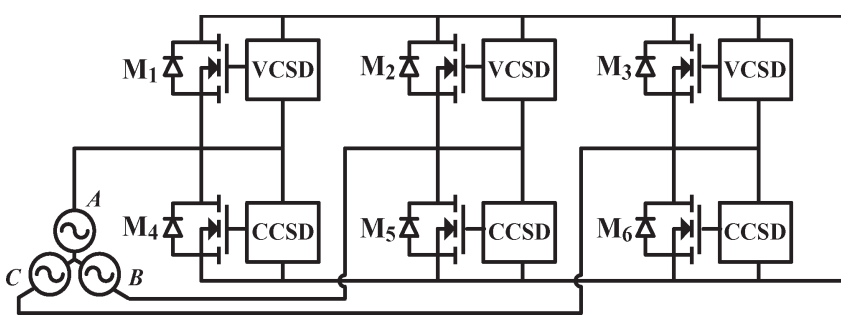

Fig. 8. Three-phase full synchronous rectifier for high-voltage applications.

and $\mathrm{M}_{10}$ is on to keep the gate-source voltage of $\mathrm{M}_{2}$ low.

2) $t_{1}-t_{2}$ : As shown in Fig. 12(b), when $v_{A B}$ becomes lower than $V$ after $t_{1}$, the current in $R_{7}$ changes its direction. $\mathrm{Q}_{4}$ is turned on, and $\mathrm{Q}_{5}$ turns off. $v_{B C 5}$ starts to be charged up from zero. Due to $\mathrm{D}_{1}$ and $\mathrm{Q}_{4}$, the gate-source voltage of $\mathrm{M}_{8}$ will follow $v_{B C 5}$. At the end of this interval, the gate-source voltage of $\mathrm{M}_{8}$ reaches its gate threshold voltage.

3) $t_{2}-t_{3}: \mathrm{M}_{8}$ begins to conduct at $t_{2} . v_{G S 1}$ starts to decrease. $v_{B C 5}$ continues to increase. Before it reaches the threshold voltage for $\mathrm{M}_{7}$ to switch off at $t_{3}, \mathrm{M}_{7}$ and $\mathrm{M}_{8}$ will simultaneously conduct, as shown in Fig. 12(c).
Somewhere in this interval, $v_{G S 1}$ will fall to the gate threshold voltage of $\mathrm{M}_{1}$ (the time of which can be slightly controlled by the proportion of $R_{3}$ and $R_{4}$ ). The interval ends when $v_{G S 1}$ falls to zero and when $\mathrm{M}_{1}$ is turned off.

4) $t_{3}-t_{4}$ : As shown in Fig. 12(d), $\mathrm{M}_{7}$ turns off at $t_{3}$, and $\mathrm{M}_{8}$ is kept on to keep $\mathrm{M}_{1}$ off. The current flows through the source-drain diode of $\mathrm{M}_{1}$. Commutation will happen at $t_{4}$.

5) $t_{4}-t_{5}$ : As shown in Fig. 12(e), when $v_{A B}$ becomes lower than zero after $t_{4}$, the current in $R_{8}$ changes its direction. $v_{B C 10}$ begins to decrease from $V$, indicating that $\mathrm{Q}_{9}$ is turned off and $\mathrm{Q}_{10}$ is turned on. While at $t_{4}, v_{B C 5}$ reaches $V$, and it will be clamped at the voltage of $C_{3}$ by the base-collector p-n junction of $\mathrm{Q}_{4}$. Meanwhile, the source-drain diode of $\mathrm{M}_{1}$ turns off, and the source-drain diode of $\mathrm{M}_{2}$ begins to conduct naturally, as shown in Fig. 12(e). The interval ends when $v_{B C 10}$ falls down to the threshold voltage for $\mathrm{M}_{9}$ to switch on.

6) $t_{5}-t_{6}$ : As shown in Fig. 12(f), $M_{9}$ begins to conduct at $t_{5}$, and $v_{B C 10}$ continues to decrease. Before $v_{B C 10}$ falls down to the gate threshold voltage of $\mathrm{M}_{10}$ at $t_{6}, \mathrm{M}_{9}$ and $\mathrm{M}_{10}$ simultaneously conduct. $v_{G S 2}$ begins to increase, and it will reach a high value at the end of the interval to turn $\mathrm{M}_{2}$ on.

7) $t_{6}-t_{7}:$ At $t_{6}, \mathrm{M}_{10}$ is turned off, and $v_{B C 10}$ continues to decrease, as shown in Fig. 12(g). The interval ends when $v_{B C 10}$ reaches zero.

8) After $t_{7}: v_{A B}$ is lower than $-V \cdot v_{B C 10}$ is clamped zero by the collector-base $p-n$ junction of $Q_{10}$, as shown in Fig. 12(h).

\section{Operation Principle of the Lower Gate Drives}

The lower MOSFETs are controlled by the "currentcontrolled" gate-drive circuits. Current-sensing resistors $R_{S 1}$ to $R_{S 3}$ and comparators are used to detect the MOSFET currents and to drive the MOSFETs. Fig. 13 shows the drive circuit of 


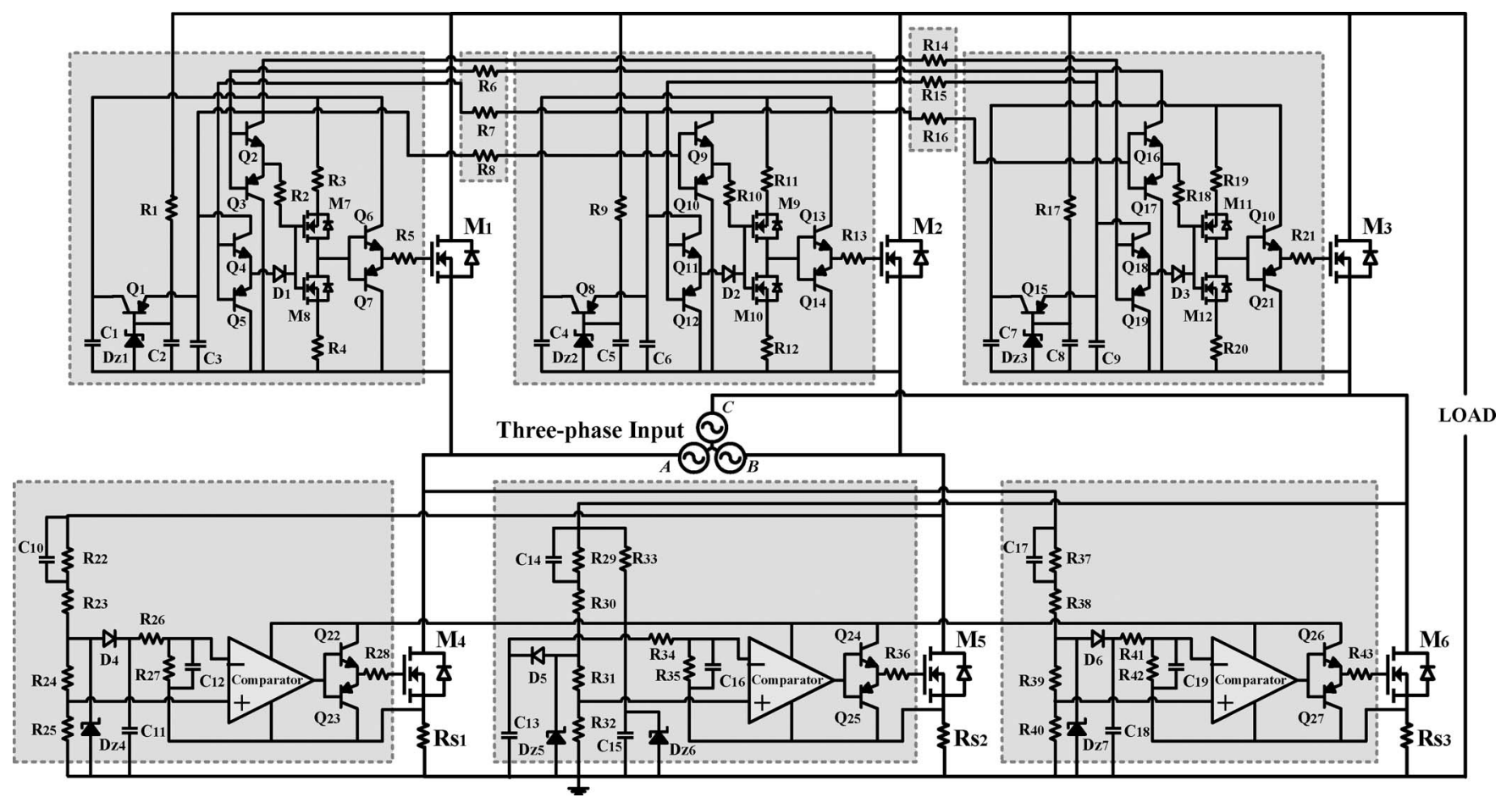

Fig. 9. Proposed three-phase self-driven synchronous rectifier.

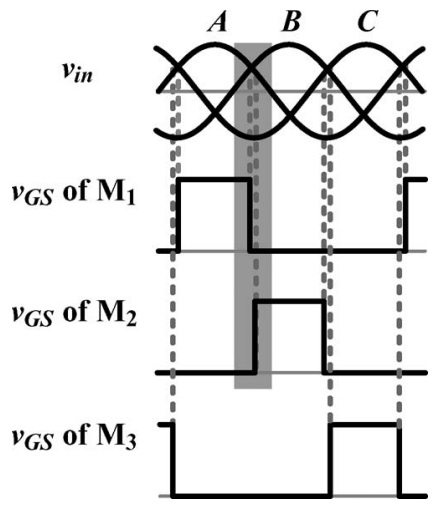

Fig. 10. Gate-source signals of the three upper MOSFETs with the input phase voltages.

$\mathrm{M}_{5}$ (phase B). $C_{13}$ is used to give a positive voltage for the inverting inputs of the comparators, which can provide a safe margin set by the potential divider comprising resistors $R_{34}$ and $R_{35}$. The voltage of $C_{15}$, stabilized by the Zener diode $\mathrm{D}_{\mathrm{Z} 6}$, is the power supply for the comparators. $C_{13}$ will be charged up to the designated voltage before the voltage of $C_{15}$ reaches a voltage that is high enough for the comparators to work. This arrangement ensures that the low-side MOSFETs $\mathrm{M}_{4}$ to $\mathrm{M}_{6}$ are switched only when the proper logic control is ready.

\section{Additional Circuits for Turning Off at Zero-Crossing Points}

The self-driven synchronous rectifier is designed to cope with the resistive, capacitive, and inductive loads. The driving waveforms of phase B for the resistive load are shown in Fig. 14. Here, $v_{C 0}$ is the input voltage of phase $\mathrm{C}$, taking the low

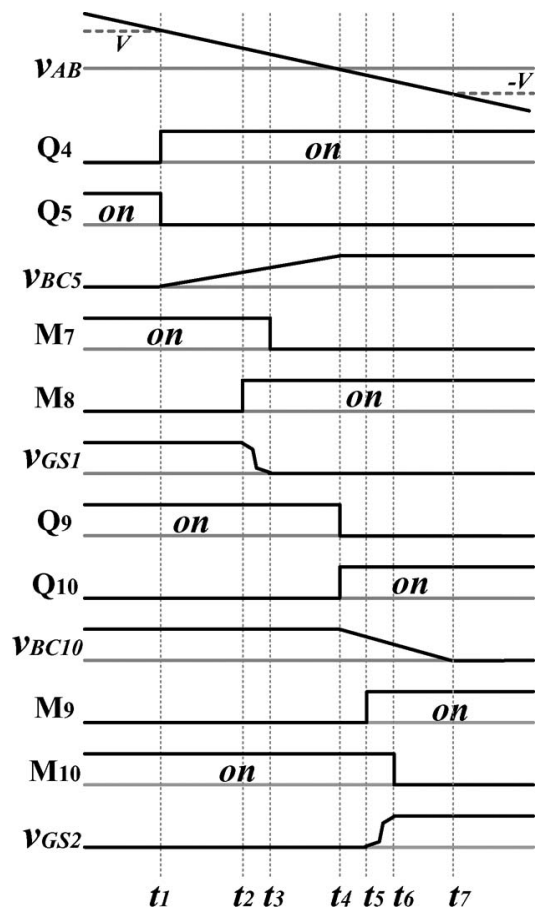

Fig. 11. Timing diagram for the high-side gate-drive circuits.

rectified voltage as reference zero (Fig. 1), and $i_{B}$ is the current flowing through $\mathrm{M}_{5}$. The current commutates with a sharp slope. The comparator may not respond quickly enough to turn off MOSFETs $\mathrm{M}_{5}$ under such a fast current change, which may cause a fatal short-circuit situation. Therefore, an extra circuit (Fig. 15) is added to provide a small positive signal to the noninverting inputs of the comparator. The signal is generated 


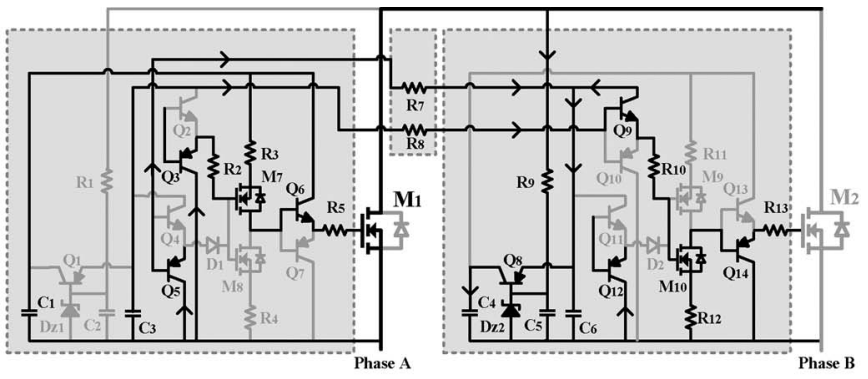

(a)

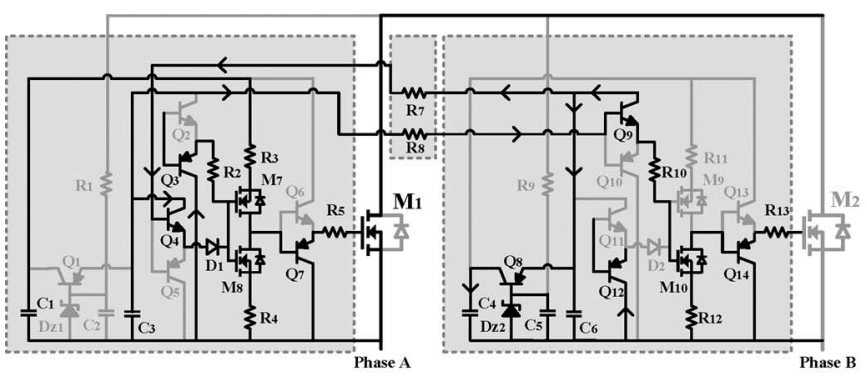

(c)

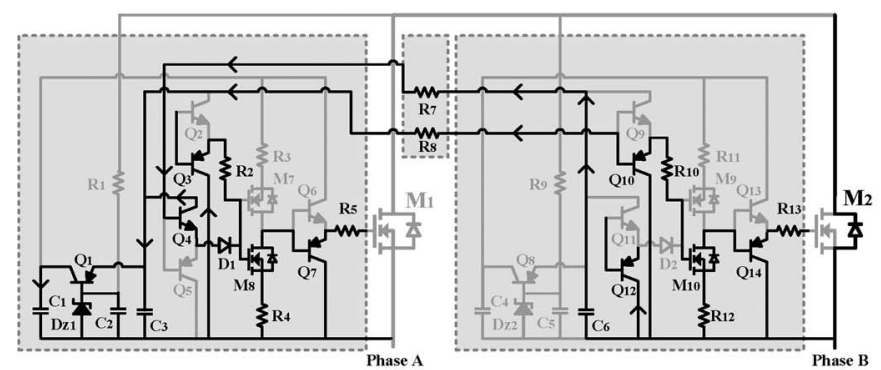

(e)

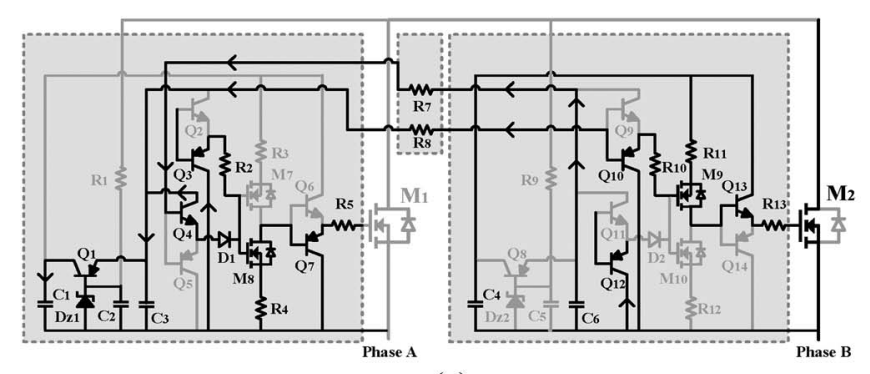

(g)

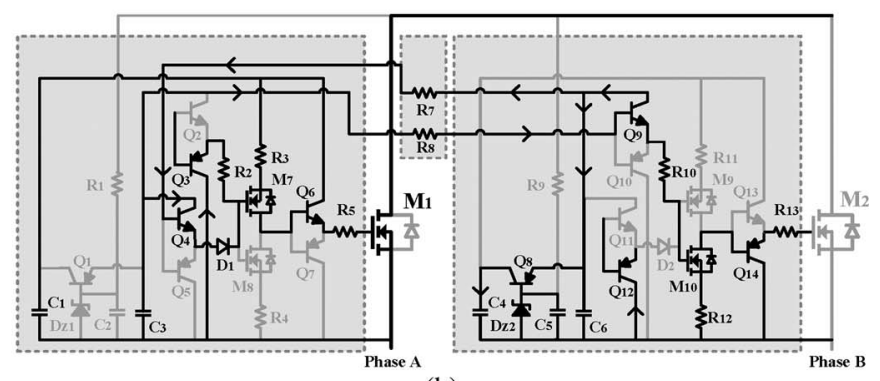

(b)

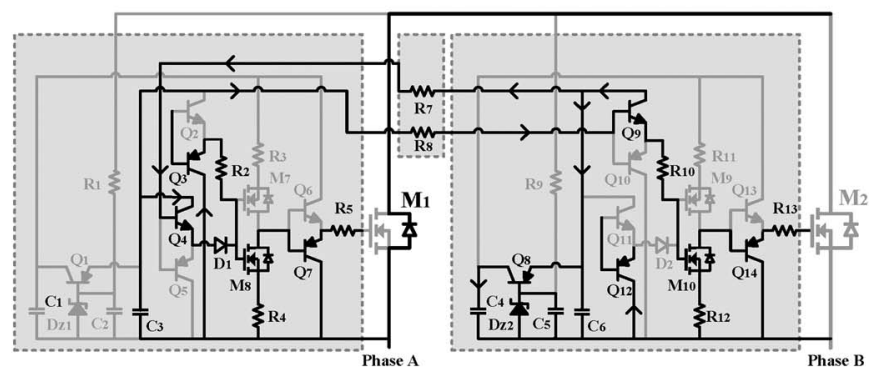

(d)

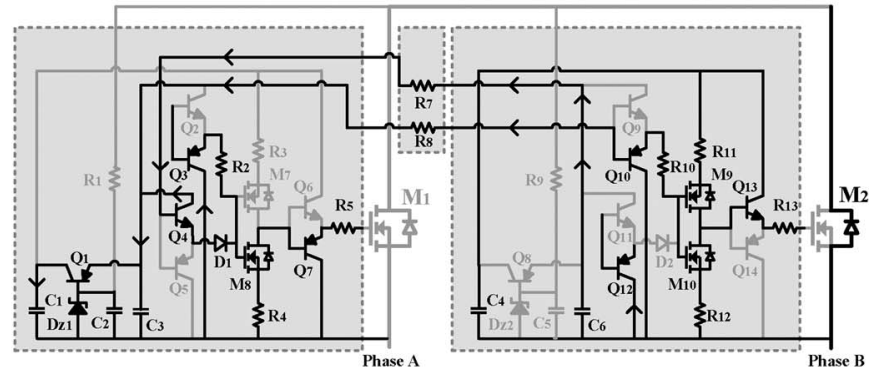

(f)

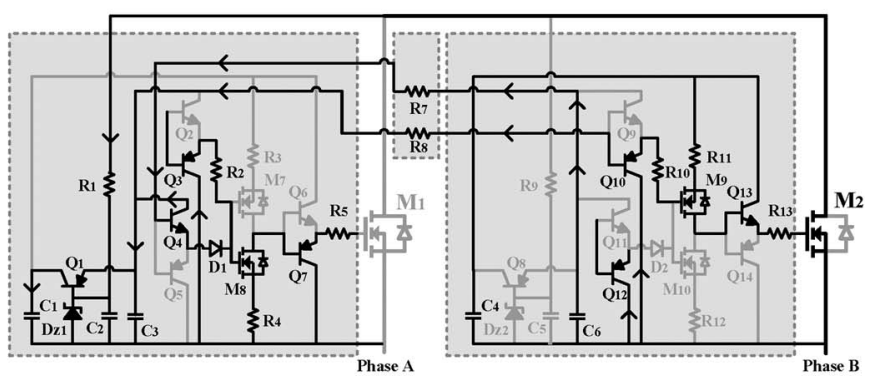

(h)

Fig. 12. Operation intervals of the proposed upper driver. (a) Before $t_{1}$. (b) $t_{1}-t_{2}$. (c) $t_{2}-t_{3}$. (d) $t_{3}-t_{4}$. (e) $t_{4}-t_{5}$. (f) $t_{5}-t_{6}$. (g) $t_{6}-t_{7}$. (h) After $t_{7}$.
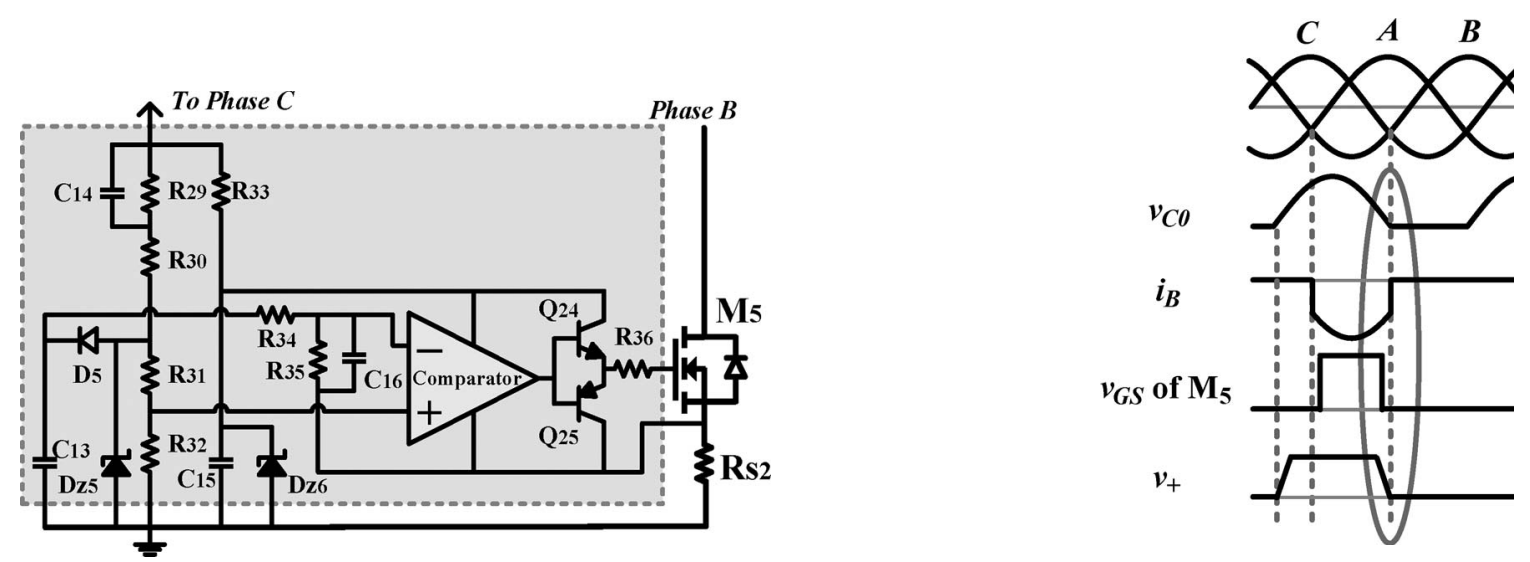

Fig. 13. Drive circuit of $\mathrm{M}_{5}$ (phase B).

Fig. 14. Driving waveforms of the phase B low-side circuit. 


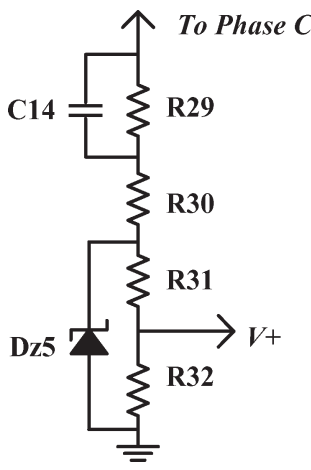

Fig. 15. Additional circuit to guarantee the comparator to turn off (phase B).

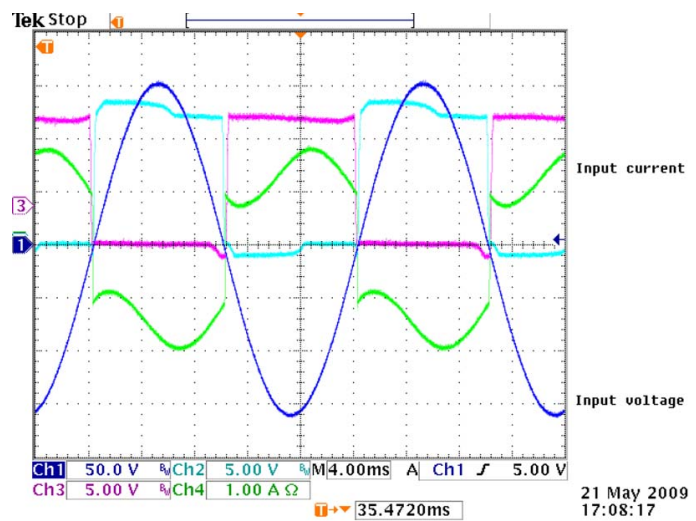

Fig. 16. (Light blue and pink) Gate voltage of the VCSD MOSFETs. (Dark blue) Input voltage. (Green) Input current [19].

from the input voltage of phase C, as shown in Fig. 14, and it can guarantee the comparator to turn off the MOSFETs in time. In Fig. $15, \mathrm{D}_{\mathrm{Z} 5}$ is a Zener diode of about $10 \mathrm{~V}$. When the $v_{C 0}$ begins to rise from zero, the voltage of $\mathrm{D}_{\mathrm{Z} 5}$ will rise until it reaches its rated voltage. Then, it will remain at this voltage with a very small fluctuation. Here, $R_{31}$ and $R_{32}$ form a voltage divider to scale down the voltage signal with a reduced fluctuation.

\section{Practical Verification}

Practical evaluations of a 2-kW single-phase SDSR based on Fig. 3 and a 2-kW three-phase SDSR based on Fig. 9 have been carried out. A diode bridge comprising diodes $60 \mathrm{EPF} 06 \mathrm{PbF}$, with a forward voltage drop of about $0.85 \mathrm{~V}$, is used to compare with an SDSR based on MOSFETs IPW60R045CP, with an ON-state resistance of $45 \mathrm{~m} \Omega$. The current and voltage waveforms are captured with the use of a Tektronix digital storage oscilloscope, and the power measurements are captured using the Voltech PM6000 Power Analyser.

\section{A. Single-Phase SDSR}

A single-phase SDSR has been tested with an inductive-resistive load $(L=133 \mathrm{mH}$ and $R=73.3 \Omega$ ). Two CCSD MOSFETs are used to replace the lower diodes, and two VCSD MOSFETs are employed to replace the two upper diodes [19]. Fig. 16 shows the two gate signals of the two

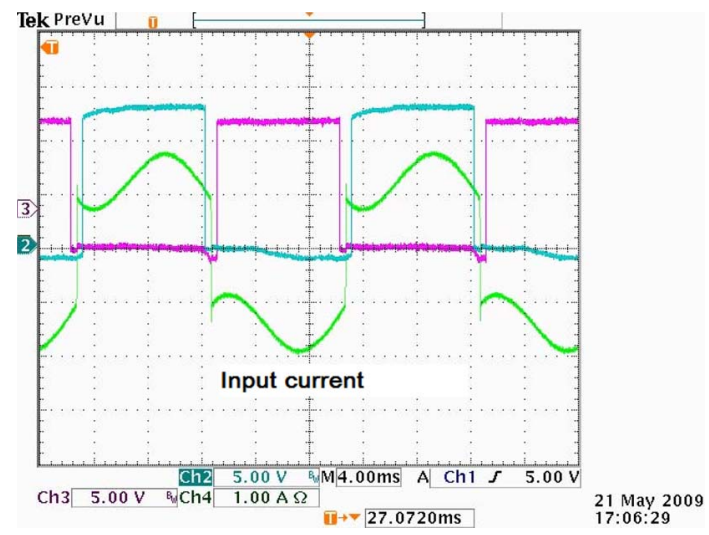

Fig. 17. (Pink and dark green) Gate voltage of the CCSD MOSFETs. (Green) Input current [19].

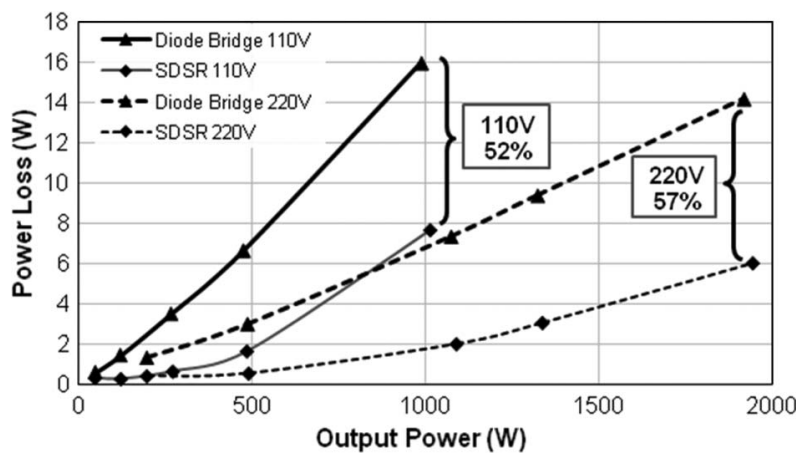

Fig. 18. Power loss comparison of the diode rectifier and the self-driven rectifier with a resistive load [19].

VCSD MOSFETs, the input ac voltage, and the input current. It can be seen that the two gate signals are synchronized with their respective half-cycles of the ac mains voltage. The corresponding gate signals of the two CCSD MOSFETs are shown with the input current in Fig. 17. The input current waveform is a typical one, as expected from a diode bridge with an $L R$ load. Fig. 18 shows a practical comparison of the power losses between this single-phase SDSR and a diode bridge. It can be seen that over $50 \%$ of the power loss reduction can be achieved.

\section{B. Three-Phase SDSR}

A three-phase SDSR has also been set up for a resistive load $(R=348 \Omega)$ and a capacitive-resistive load $(C=470 \mu \mathrm{F}$ and $R=73.3 \Omega$ ). Similar to the situation in the single-phase case, the upper MOSFETS are voltage controlled, and the lower MOSFETS are current controlled. For comparison, Vishay diodes 60EPF06PBF and Infineon Mosfets IPW60R045CP are used in the tests. Fig. 19 shows the measured gate voltages of the three lower CCSD MOSFETs and the corresponding input current of one phase. It can be observed that the three lower switches conduct $120^{\circ}$ per cycle as expected, and the phase current is similar to that expected from a standard threephase diode rectifier with a resistive load. The measured gate voltages of the upper MOSFETs and the output voltage of the three-phase SDSR are shown in Fig. 20. These practical 


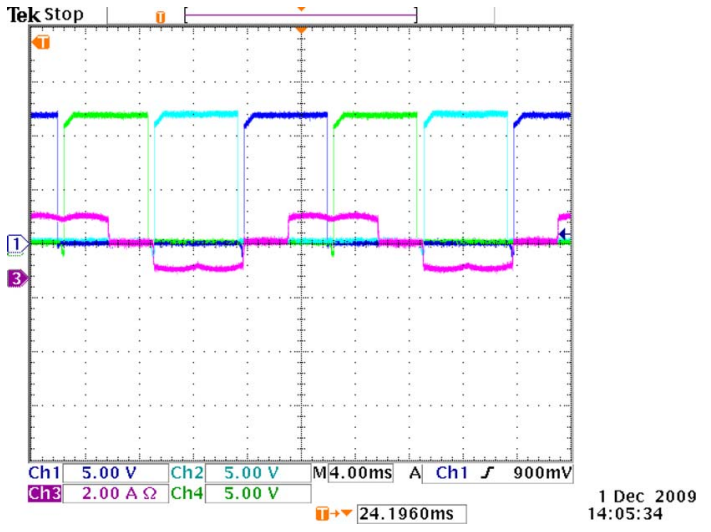

Fig. 19. Gate-source voltages of the lower (CCSD) MOSFETs and the input current of one phase (pink) for a resistive load.

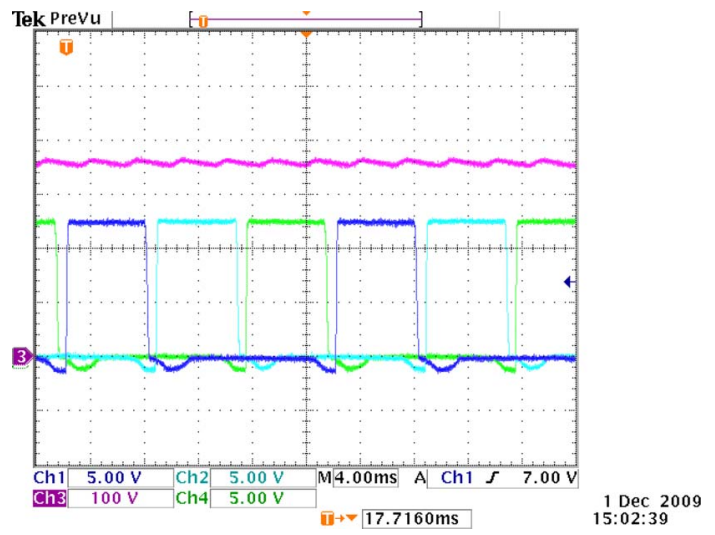

Fig. 20. Gate-source voltages of the upper (VCSD) MOSFETs and the output voltage (pink) for a capacitive-resistive load.

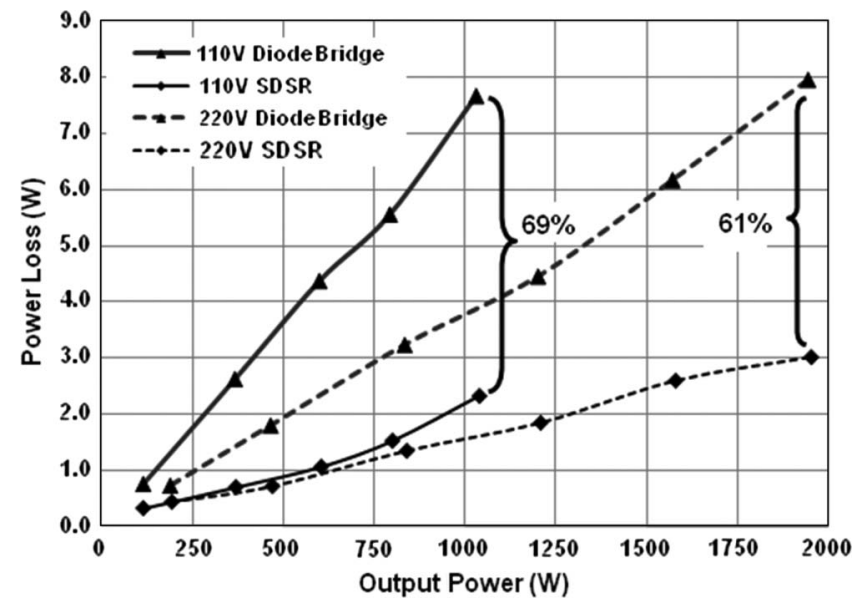

Fig. 21. Power loss comparison of a three-phase diode rectifier and a selfdriven synchronous rectifier with a resistive load.

measurements confirm the operation of the multiphase SDSR. Fig. 21 shows the practical comparison of the power losses between a three-phase diode rectifier and a three-phase SDSR for a resistive load. It is found that over $60 \%$ of the power loss can be reduced.

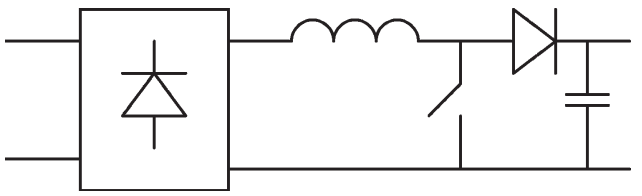

Fig. 22. Schematic of a boost-type power factor correction circuit with a frontend diode rectifier.

\section{Application as a Front AC-DC Stage for a $100-\mathrm{kHz}$ Boost-Type Power Factor Correction Circuit}

The scheme of a 750-W boost-type power factor correction is shown in Fig. 22. The switching frequency of the boost converter is $100 \mathrm{kHz}$, and the converter is operated at the continuous conduction mode. This system is designed for a universal input voltage from 96 to $264 \mathrm{~V}$ and a dc output voltage of $400 \mathrm{~V}$. In order to evaluate the efficiency improvement, the diode bridge is replaced by a self-driven synchronous rectifier, as shown in Fig. 23. Both the original and modified circuits are tested at 110 and $220 \mathrm{~V}$. The energy efficiency plots of the two schemes are shown in Fig. 24. It can be seen that a power loss reduction of over $50 \%$ in the rectification power stage can be achieved. The measured input voltage, input current, and dc output voltage of the modified system are shown in Fig. 25. The power factor is found to be 0.99 . These waveforms are essentially identical to those of the original systems. These practical measurements confirm that the SDSR can replace the diode bridge in a standard power factor correction circuit without affecting the waveforms and power factor. Since a reduction of almost $7 \mathrm{~W}(\sim 1 \%)$ can be achieved in a small diode rectifier circuit, the thermal stress of the rectifier circuit can be reduced, and a less heat sink requirement would be needed using the SDSR.

\section{CONCLUSION}

This paper has presented the fundamental concept of a generalized SDSR technique that can be extended to the multiphase rectifier systems. Unlike the existing synchronous rectifiers designed for the high-frequency power converters, the proposed self-driven synchronous rectifiers can be operated at mains frequencies. This principle stresses the need for at least one current-controlled (CCSD) MOSFET in each current loop of the synchronous rectifier so that the MOSFET can be switched off when the current reverses (i.e., like the current reverse recovery of a diode). Consequently, there is no need to design a sophisticated control logic to control the MOSFETs.

The principle has been successfully demonstrated in practical single- and three-phase systems up to $2 \mathrm{~kW}$. The measurements have confirmed that a significant power loss reduction in the range of 50\%-69\% can be achieved. Further power loss can, in principle, be achieved by using parallel power MOSFETs to reduce the ON-state resistance. Since the diode rectifiers are widely used components in many electronic and electrical applications, the proposed principle can be used to design lowloss replacements for these diode rectifiers. With a significant reduction in the power loss, the temperature rise of the rectifier can be reduced, thus resulting in the reduction of the heat sink requirement for the overall circuit (i.e., higher compactness and 


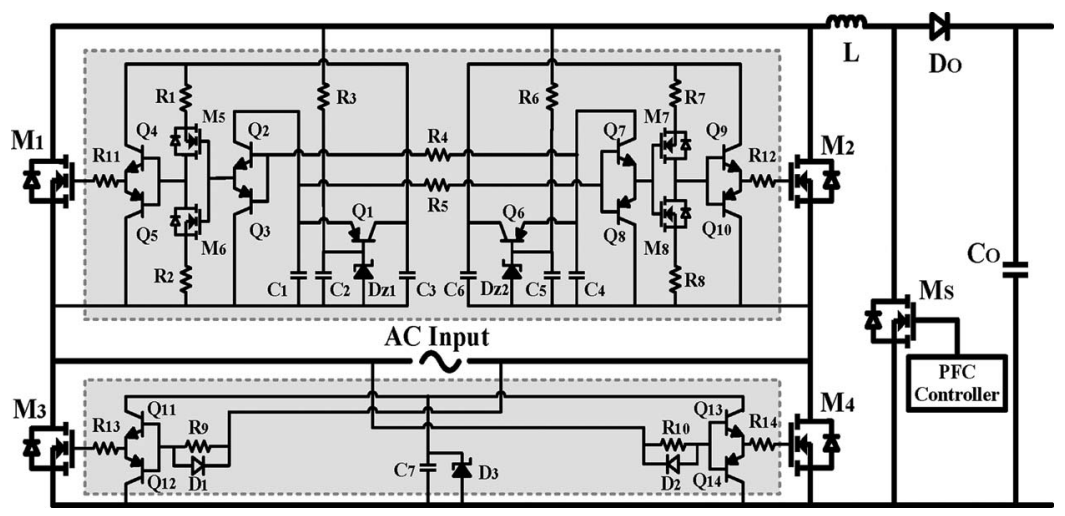

Fig. 23. Modified boost-type power factor correction circuit, with the diode rectifier replaced by an SDSR.

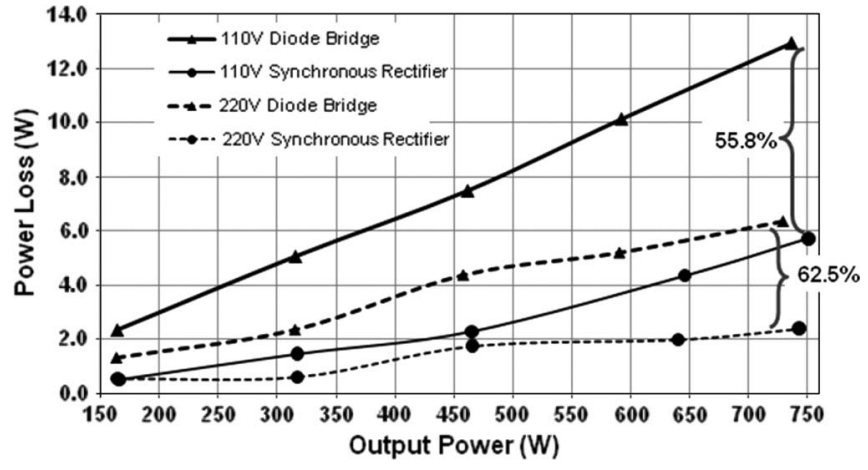

Fig. 24. Power loss comparison of the diode rectifier and the proposed SDSR in the 750-W boost-type power factor correction circuit, with a constant switching frequency of $100 \mathrm{kHz}$.

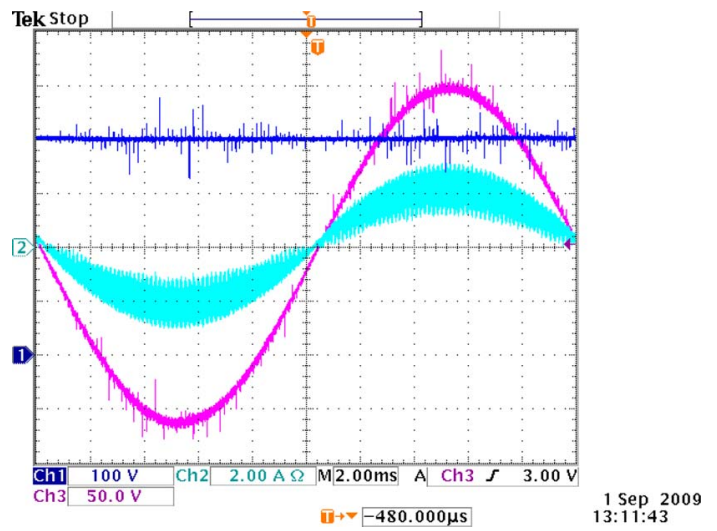

Fig. 25. (Pink) Input voltage, (green) input current, and (blue) output voltage of the boost-type power factor correction, with the diode rectifier replaced by the proposed SDSR.

power density) and also improvements in the system lifetime and reliability.

\section{ACKNOWLEDGMENT}

The authors would like to thank ConvenientPower, Ltd. for its permission to use some information in [18].

\section{REFERENCES}

[1] W. A. Tabisz, F. C. Lee, and D. Y. Chen, "A MOSFET resonant synchronous rectifier for high-frequency dc/dc converters," in Proc. 21st Аnnи. IEEE Power Electron. Spec. Conf. Rec., Jun. 11-14, 1990, pp. 769-779.
[2] K. Fukushima, T. Hashimoto, T. Ninomiya, and T. Segawa, "Analysis of abnormal phenomenon in common-source-type forward converter with self-driven synchronous rectifier," in Proc. CES/IEEE 5th IPEMC, Aug. 14-16, 2006, vol. 2, pp. 1-5.

[3] K. Murata, K. Harada, and T. Harimoto, "Self turn-on loss of MOSFET as synchronous rectifier in dc/dc buck converter-In case of a low driving impedance," in Proc. IEEE Power Electron. Spec. Conf., Jun. 15-19, 2008, pp. 3348-3353.

[4] J.-J. Lee, J.-M. Kwon, E.-H. Kim, W.-Y. Choi, and B.-H. Kwon, "Singlestage single-switch PFC flyback converter using a synchronous rectifier," IEEE Trans. Ind. Electron., vol. 55, no. 3, pp. 1352-1365, Mar. 2008.

[5] R. Jaschke, "Conduction losses in dc/dc-converters as buckboost/ boostbuck synchronous rectifier types," in Proc. CPE, May 29-Jun. 1, 2007, pp. 1-10.

[6] E. Adib and H. Farzanehfard, "Zero-voltage-transition PWM converters with synchronous rectifier," IEEE Trans. Power Electron., vol. 25, no. 1, pp. 105-110, Jan. 2010.

[7] G.-Y. Jeong, "High efficiency asymmetrical half-bridge converter using a self-driven synchronous rectifier," IET Power Electron., vol. 1, no. 1, pp. 62-71, Mar. 2008.

[8] X. Wu, G. Hua, J. Zhang, and Z. Qian, "A new current-driven synchronous rectifier for series-parallel resonant $(L L C)$ dc-dc converter," IEEE Trans. Ind. Electron., vol. 58, no. 1, pp. 289-297, Jan. 2011.

[9] D. Fu, Y. Liu, F. C. Lee, and M. Xu, "A novel driving scheme for synchronous rectifiers in $L L C$ resonant converters," IEEE Trans. Power Electron., vol. 24, no. 5, pp. 1321-1329, May 2009.

[10] J. A. Cobos, P. Alou, O. Garcia, J. Uceda, and M. Rascon, "New driving scheme for self driven synchronous rectifiers," in Proc. 14th Anпи. IEEE APEC, Mar. 14-18, 1999, vol. 2, pp. 840-846.

[11] E. Janssen, "GreenChip SR: Synchronous rectifier controller IC," in Proc. IEEE Int. Symp. Ind. Electron., Jun. 4-7, 2007, pp. 2319-2325.

[12] H. Mao, O. Abdel Rahman, and I. Batarseh, "Zero-voltage-switching dc-dc converters with synchronous rectifiers," IEEE Trans. Power Electron., vol. 23, no. 1, pp. 369-378, Jan. 2008.

[13] B.-H. Kwon, J.-H. Youm, and J.-W. Lim, "A line-voltage-sensorless synchronous rectifier," IEEE Trans. Power Electron., vol. 14, no. 5, pp. 966-972, Sep. 1999.

[14] R. Portillo, J. M. Carrasco, J. I. Leon, E. Galvan, and M. M. Prats, "Modeling of five-level converter used in a synchronous rectifier application," in Proc. IEEE 36th Power Electron. Spec. Conf., Jun. 16, 2005, pp. 1396-1401.

[15] B. Vaysse, "Mosgate device driver for synchronous rectification of a 3-phase sinusoidal source,” U.S. Patent 6765 425, Jul. 20, 2004.

[16] M. I. Mihaiu, "Toward the 'ideal diode' using power MOSFET in full wave synchronous rectifiers for low voltage power supplies," in Proc. Int. SPEEDAM, Jun. 11-13, 2008, pp. 1384-1387.

[17] W. C. Ho, S. Y. R. Hui, and X. Liu, "Single-phase self-driven fullbridge synchronous rectification." U.S. patent application: US12/194,921, Aug. 20, 2008

[18] W. C. Ho, S. Y. R. Hui, X. Liu, and W. P. Choi, "Generalized ac-dc synchronous rectification techniques for single- and multi-phase systems," U.S. patent application: US 12/274,469, Nov. 20, 2008.

[19] W. X. Zhong, W. C. Ho, X. Liu, and S. Y. R. Hui, "Self-driven ac-do synchronous rectifier for power applications-A direct energy-efficient replacement for traditional diode rectifier," in Proc. IEEE Appl. Power Electron. Conf., 2010, pp. 994-1001. 


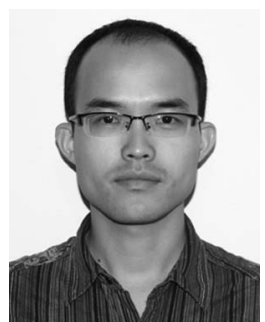

W. X. Zhong was born in China in 1984. He received the B.S. degree in electrical engineering from Tsinghua University, Beijing, China, in 2007. He is currently working toward the Ph.D. degree in the Center for Power Electronics, City University of Hong Kong, Kowloon, Hong Kong.

His current research interests include synchronous rectification and wireless power transfer.

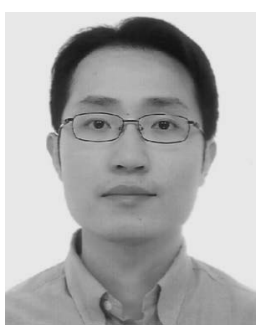

W. P. Choi received the B.Eng. degree in mechanical engineering from The University of Hong Kong, Hong Kong, in 1999 and the Higher Cert. in electronic engineering from HKIVE, Hong Kong, in 2003. He is currently working toward the M.Phil. degree in the Department of Electronic Engineering, City University of Hong Kong, Hong Kong.

He was working as a Mechanical Design Engineer in a semiconductor equipment company and also as an Electronic Design Engineer in an ac/dc adapter and battery charger company. He is currently a Technical Product Manager with a wireless power appliance company. His research interests include modeling, control, and optimization of wireless power transfer.

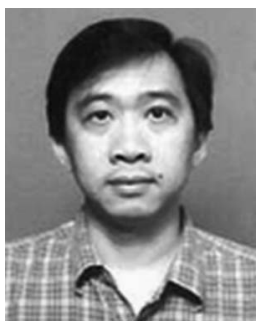

Wing W. C. Ho (M' 86) received the B.E.Sc. degree in electrical engineering and the B.Sc. degree in applied mathematics from the University of Western Ontario, London, ON, Canada, in 1986, the Ph.D. degree in electrical engineering from the University of Hong Kong, Kowloon, Hong Kong, in 1997, and the M.B.A. degree from the University of Newcastle, Newcastle, NSW, Australia, in 2003.

$\mathrm{He}$ is a part-time Research Fellow with the City University of Hong Kong, Kowloon, Hong Kong and is currently a technical staff with Traxon Technolo-

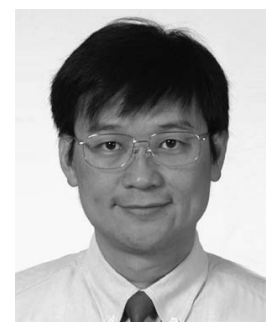

S. Y. (Ron) Hui (F'03) received the B.Sc. Hons degree in engineering from the University of Birmingham, Birmingham, U.K., in 1984 and the D.I.C. and Ph.D. degrees from the Imperial College of Science and Technology, London, U.K., in 1987.

$\mathrm{He}$ was a Lecturer with the University of Nottingham, Nottingham, U.K., in 1987-1990. In 1990, he joined the University of Technology, Sydney, NSW, Australia. He was appointed as a Senior Lecturer with the University of Sydney, Sydney, in 1992, where he became a Reader in 1995 . He joined the City University of Hong Kong (CityU), Kowloon, Hong Kong, as a Professor in 1996 and was promoted as a Chair Professor in 1998. In 2001-2004, he served as an Associate Dean of the Faculty of Science and Engineering, CityU. Since 2010, he has been holding the Chair Professorship at both CityU and Imperial College London. He has published over 200 technical papers, including more than 140 refereed journal publications and book chapters. Over 45 of his patents have been adopted by the industry.

Dr. Hui is a Fellow of the Institution of Engineering and Technology (IET). He has been an Associate Editor of the IEEE TRAnsaCtions ON POWER ELECTRONICS since 1997 and an Associate of the IEEE TRANSACTIONS ON INDUSTRIAL ElECTRONICS since 2007. He was appointed twice as an IEEE Distinguished Lecturer by the IEEE Power Electronics Society in 2004 and 2006. He served as one of the 18 Administrative Committee members of the IEEE Power Electronics Society, and he was the Chairman of its Constitution and Bylaws Committee from 2002 to 2010. He received the Teaching Excellence Award at CityU in 1998 and the Earth Champion Award in 2008. He received the IEEE Best Paper Award from the IEEE IAS Committee on Production and Applications of Light in 2002 and two IEEE Power Electronics Transactions Prize Paper Awards for his publication in wireless battery charging platform technology in 2009 and for his paper on LED system theory in 2010. His inventions on wireless charging platform technology underpin key dimensions of the world's 1st wireless power standard "Qi." In November 2010 he received the IEEE Rudolf Chope R\&D Award from the IEEE Industrial Electronics Society and the IET Achievement Medal (The Crompton Medal), and he was elected to the Fellowship of the Australian Academy of Technological Sciences \& Engineering. 